\title{
A atuação do Ministério Público por meio da auditoria nas fundações: da conformidade dos procedimentos de controle à proteção do patrimônio
}

\author{
Vanessa Fonseca Tomazini ${ }^{1}$ \\ Vera Sirlene Leonardo ${ }^{2}$
}

\begin{abstract}
Resumo: Uma das formas de mobilização da sociedade em prol dos fins sociais se dá por meio das atividades desenvolvidas por fundações privadas que devem submeter as suas atividades e a gestão dos recursos à auditoria do Ministério Público. Assim, a pesquisa aborda a ação do Ministério Público no seu papel de indutor e fortalecedor do controle do patrimônio das fundações e a sua atuação de velamento e de verificação da conformidade dos procedimentos de controle dessas entidades. O objetivo da pesquisa é analisar a conformidade nas prestações de contas das fundações privadas realizadas por meio de relatórios de auditoria emitidos pelo Órgão Ministerial. A pesquisa é empírico-teórica, qualitativa, estudo de caso quanto à estratégia de pesquisa, com dados levantados por meio de entrevista semiestruturada e documentos oficiais, cuja unidade de análise são três fundações privadas localizadas no município de Maringá, Estado do Paraná. Os resultados da análise evidenciaram que as prestações de contas das fundações não seguem fielmente os preceitos regulamentares, passam por inúmeras intervenções dos auditores até que as informações estejam em conformidade legal. As não conformidades atrasam o processo de prestação de contas e comprometem a veracidade das informações. $\mathrm{O}$ estudo evidencia que o papel do MP vai além do simples cumprimento de um dever legal, atua como órgão orientador de forma que o patrimônio e as atividades das entidades sejam de fato voltados para o fim social.
\end{abstract}

Palavras-chave: Ministério Público. Auditoria. Fundações. Prestação de contas.

Abstract: One of the ways of mobilizing society for social purposes is through activities carried out by private foundations that must submit their activities and the management of resources to the audit of the Public Ministry. Thus, the research discuss the action of the Public Ministry in its role of inductor and strengthening of the control of the patrimony of the foundations and its act of concealment and verification of the conformity of the control procedures of these entities. The purpose of the research is to analyze compliance in the accounts of private foundations through audit reports issued by the Ministerial Body. The research is empirical-theoretical, qualitative, case study regarding the research strategy, with data collected through a semi-structured interview and official documents, whose unit of analysis are three private foundations located in the municipality of Maringá, Paraná State. The results of the analysis have shown that the accounts of the foundations do not faithfully follow the regulatory precepts, they go through numerous auditors' interventions until the information is legally compliant. Nonconformities delay the accountability process and compromise the veracity of the information. The study evidences that the role of the MP goes beyond the simple fulfillment of a legal duty, acts as a guiding organ so that the patrimony and the activities of the entities are in fact directed toward the social purpose.

Keywords: Public Ministry. Audit. Foundations. Accountability.

\footnotetext{
${ }^{1}$ Graduada em Ciências Contábeis pela Universidade Estadual de Maringá. E-mail: vanft@hotmail.com.

2 Docente da Universidade Estadual de Maringá. Doutora em Administração Pública e Governo pela Fundação Getúlio Vargas, São Paulo. E-mail: vsleonardo2@gmail.com.
}

Página 132 Caderno de Ciências Sociais Aplicadas, Vitória da Conquista/BA, vol. 15, n 26, ano 15, p. 132-150, jul/dez 2018. 


\section{Introdução}

O Ministério Público (MP), como órgão de accountability horizontal no sistema político brasileiro, tem como responsabilidade, entre as diversas frentes de atuação, o velamento das fundações privadas, conforme artigo $66^{\circ}$ do Código Civil Brasileiro. Essa atuação consiste em defender os interesses da sociedade por meio da fiscalização do controle e do auxílio às entidades do Terceiro Setor: as fundações privadas.

As fundações, respeitados os requisitos previstos na Constituição Federal do Brasil, Código Tributário Nacional e legislações aplicáveis a tributos específicos, podem usufruir de imunidades e isenções tributárias e receber repasses financeiros do poder público para exercer as suas atividades. Além de origem pública, os recursos podem ser provenientes de pessoas físicas e de empresas, além dos que podem ser gerados pela própria entidade.

Em decorrência disto, as fundações devem prestar contas quanto à eficácia de sua gestão, de forma a evidenciar se os recursos são, de fato, revertidos para os fins propostos conforme previsto no seu Estatuto Social. É nesse sentido que dois aspectos são verificados na fiscalização das contas das fundações: a avaliação de seu patrimônio e a forma da aplicação desse patrimônio por meio da análise e avaliação das atividades desenvolvidas.

Contudo, o estudo evidencia a múltipla atuação do MP que vai além do simples cumprimento do dever de fiscalização, apontando para uma atuação voltada para a orientação dessas entidades no sentido de incentivar a adequação e evitar a reprovação das contas, admitindo frequentes correções na prestação e contas.

São os auditores do MP os responsáveis por emitir parecer sobre a regularidade das prestações de contas das fundações, que, após todos os procedimentos de verificação, emitem o relatório de auditoria o qual deve ser fundamentado nos princípios e nas normas brasileiras de contabilidade, além de outras regulamentações.

Diante desse contexto, essa pesquisa propõe como objetivo analisar a conformidade nas prestações de contas das fundações privadas realizadas por meio de relatórios de auditoria emitidos pelo Órgão Ministerial. O estudo analisa os apontamentos apresentados nos relatórios de auditoria das prestações de contas de três fundações privadas apresentadas ao Ministério Público do Estado do Paraná (MPPR). Para tanto, faz-se a seguinte pergunta de pesquisa: as prestações de contas das

Página 133 Caderno de Ciências Sociais Aplicadas, Vitória da Conquista/BA, vol. 15, nº 26, ano 15, p. 132-150, jul/dez 2018. 
fundações analisadas estão de acordo com os princípios e as normas brasileiras de contabilidade, Resolução 2.434/02 e demais legislações aplicadas a situações específicas, de modo a demonstrar boa gestão dos recursos e o atendimento às finalidades propostas pelas entidades?

A relevância do estudo no meio acadêmico, como destacado por Bettiol Júnior (2005), decorre do número pequeno de pesquisadores quando o tema é Terceiro Setor no Brasil. Além disso, o estudo resgata a importância da contabilidade do Terceiro Setor como um instrumento de gestão, transparência e accountability.

O trabalho organiza-se após essa introdução nos tópicos que apresentam a relação entre o Ministério Público e as fundações privadas e a prestação de contas das fundações. $\mathrm{Na}$ sequência discorre-se sobre a metodologia e na apresentação dos resultados são caracterizadas as fundações e os apontamentos em relatórios de auditoria. Por fim, apresentam-se as considerações finais.

\section{Ministério Público e as fundações privadas: o Ministério Público como indutor e fortalecedor do controle do patrimônio das fundações}

A designação do MP como um órgão regulatório das fundações está ligado à sua função de zelar pelo público, de proteger as atividades públicas. Isto porque as atividades das fundações "são, tipicamente, públicas, apesar de serem pessoas jurídicas de direito privado” (MELO, 2010, p. 4). Além disso, para o alcance da finalidade pública "sua constituição ocorre através de uma dotação patrimonial" (TORRES, 2007, p. 66).

Compete ao MP acompanhar as fundações durante toda sua existência a fim de garantir que o patrimônio constituído para dar vida a estas entidades seja de fato empregado para as finalidades públicas a que se propõe. O que garante este poder ao órgão é o Código Civil Brasileiro, ao fixar, no artigo $66^{\circ}$, que, verbis, "velará pelas fundações o Ministério Público do Estado onde situadas" (BRASIL, 2002).

Para entender de que forma ocorre o velamento do MP pelas fundações privadas, este estudo fundamentou-se em Santos e Silveira (2007) que enfatizam que o ato de velamento fundamenta-se no assessoramento e análise das entidades por meio da apreciação de suas prestações de contas. Acrescenta-se que o termo velamento refere-se ao estado de "estar de sentinela (exercer vigilância), e também patrocinar e proteger", segundo Resende (2007, p. 127).

Página 134 Caderno de Ciências Sociais Aplicadas, Vitória da Conquista/BA, vol. 15, n 26, ano 15, p. 132-150, jul/dez 2018. 
Esse controle contínuo desempenhado pelo MP não lhe permite apenas tomar as medidas necessárias ao se verificar má utilização do patrimônio das fundações, mas, também, lhe permite agir antecipadamente, ou seja, prevenir que o patrimônio seja dilapidado por meio do controle patrimonial que ocorre por meio das prestações de contas.

$\mathrm{O}$ ato de velamento, sentinela, controle contínuo ou outro termo similar significa que o MP pode evitar que as fundações sejam usadas para aproveitamento dos benefícios concedidos, assim como para ações mal intencionadas, pois:

Tais entidades suprem ou cooperam com a organização estatal no atendimento à coletividade, recebendo, por tal motivo, benefícios fiscais e/ou tributários do Governo. Tais fatos, além de envolver questões de interesse geral, ampliam a possibilidade de que pessoas desonestas tentem se utilizar dessas entidades para se locupletarem ilicitamente, o que só pode ser evitado com um efetivo velamento por algum dos órgãos de defesa do interesse coletivo (RESENDE, 2007, p. 141).

O entendimento de Melo (2010) vem ao encontro ao que se pretende mostrar com esta pesquisa ao indicar que além da fiscalização, o MP tem papel incentivador para as fundações, já que, quem protege o que lhes dão vida (patrimônio) incentiva sua continuidade e o bem coletivo a que se propõe.

De acordo com Torres (2007, p. 66), "faz-se necessário o controle através de um ente público, que seja responsável por acompanhar as contas, o patrimônio e as atividades desenvolvidas pela fundação". As contas das fundações devem estar em conformidade com as normas previstas na Lei 4.320/64, na Resolução CFC 837/99 e na Resolução 2.434/02 do Ministério Público do Estado do Paraná.

O MP pode intervir de forma direta no gerenciamento da entidade se detectar irregularidades, e possui os meios necessários para a instalação de inquéritos (TORRES, 2007). Cabe complementar que as fundações estão sujeitas às penalidades pelos atos de improbidade praticados contra o patrimônio da entidade, conforme previsto na Lei 8.429/92 (BRASIL, 1992).

Além da fiscalização, o MP tem papel incentivador para as fundações, uma vez que, segundo Melo (2010, p. 5):

[...] passa para elas a ser também órgão incentivador e fiscalizador. Assim é que surge de plano uma identificação entre ele e as fundações, que poderíamos mesmo chamar de empatia, eis que ambos são, em última análise, instrumentos do Direito Social (MELO, 2010, p. 5).

Página 135 Caderno de Ciências Sociais Aplicadas, Vitória da Conquista/BA, vol. 15, n 26, ano 15, p. 132-150, jul/dez 2018. 
O MP “fiscalizará a constituição, a administração, a contabilidade, a realização dos fins para os quais a fundação foi criada, as alterações estatutárias, enfim, todas as atividades práticas de velamento" (BRITTES, 2016, p. 1-2). Segundo o autor, o velamento não se constitui unicamente em tarefa burocrática "mas em um conjunto de atividades destinadas a defesa do interesse social".

A relação entre o Ministério Público e as fundações privadas se dá principalmente por meio das prestações de contas. Cabe salientar que independentemente de receberem recursos públicos, as fundações deverão prestar contas ao MP, e quando ingressarem recursos de origem pública, conforme Torres (2007, p. 67), deverão prestar contas também ao Tribunal de Contas do Município.

\section{Prestação de contas das fundações privadas ao Ministério Público}

A verificação da conformidade e os procedimentos de controle do patrimônio são verificados pelo MP de forma contínua por meio das prestações de contas todos os anos. A atuação do MP é dirigida às fundações para assegurar que o patrimônio destas entidades seja de fato revertido para os fins propostos.

A pesquisa mostra que os aspectos verificados na fiscalização das contas das fundações é a avaliação de seu patrimônio e a aplicação desse patrimônio por meio da avaliação das atividades desenvolvidas.

Essa avaliação do patrimônio inclui intrinsecamente a contabilidade, o que faz com que as prestações de contas sejam apreciadas por pessoal técnico. Trata-se dos auditores que são servidores do $\mathrm{MP}$, os quais assessoram os Promotores de Justiça, no caso, os Promotores de Justiça que atuam na área de Terceiro Setor. Cabe salientar que quem aprovará ou não as contas será o Promotor, que conta com o trabalho dos auditores para consubstanciar sua decisão.

Quanto às exigências solicitadas às fundações, “em função da independência de cada Ministério Público, pode haver diferentes exigências, devendo os gestores e os contabilistas se informarem no órgão do Ministério Público incumbido do exame da prestação de contas” (CFC, 2008, 83). Portanto, as fundações devem buscar informações junto ao MP Estadual ou Federal a que pertence.

No MPPR após elaboradas, as Prestações de Contas devem ser apresentadas ao MP na forma de arquivo magnético, acompanhadas de Recibo de Entrega e Carta de Representação da 
Administração. Esclarece-se que na Carta de Representação os administradores da Fundação atestam a veracidade das informações prestadas, portanto, responsabilizando-se pelas mesmas.

A Promotoria pode solicitar prestação de contas retificadora, caso algum dado deixe de ser informado ou esteja incorreto. O processo de prestação de contas conforme o Sistema de Cadastro e Prestação de Contas (SICAP) por ser visualizado na figura 1:

Figura 1 - Processo de prestação de contas por meio do SICAP

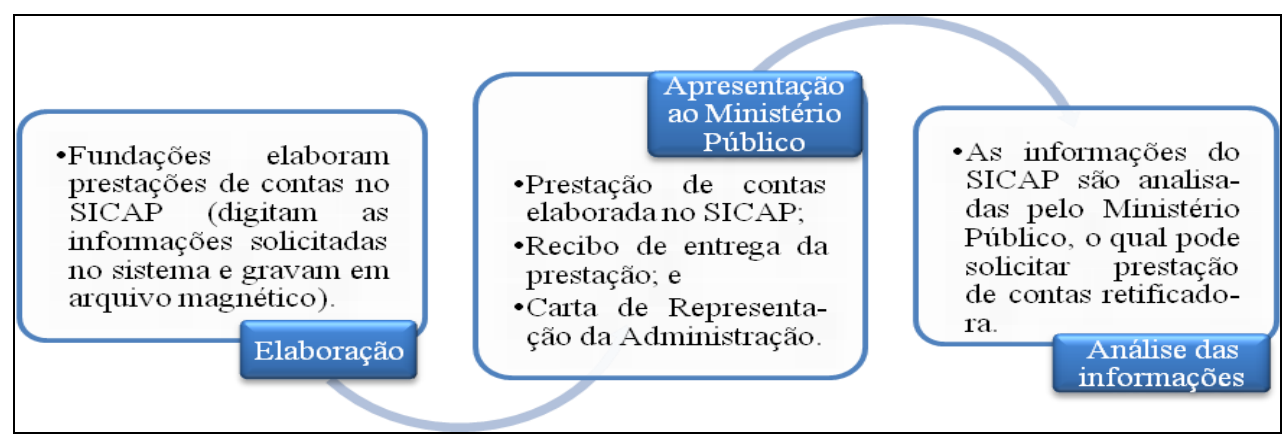

Fonte: Dados coletados em pesquisa

Além das informações prestadas no SICAP, as fundações devem apresentar vários documentos à Promotoria Pública. São exigidos, entre outros, os livros contábeis, extratos bancários, comprovantes das despesas e receitas para que os auditores possam realizar uma verificação mais abrangente, avaliando-se os documentos que deram suporte às informações prestadas e emitir parecer conclusivo sobre a regularidade das contas da fundação.

$\mathrm{O}$ artigo $48^{\circ}$ da Resolução 2.434/02 assegura aos auditores o "livre acesso às instalações, documentos e informações das Fundações, mediante a apresentação de identificação funcional e carta de apresentação emitida pela Promotoria das Fundações”.

As fundações também devem apresentar à Promotoria das Fundações, de acordo com o artigo $44^{\circ}$ da Resolução 2.434/02, antes do início de cada exercício financeiro, com relação ao ano seguinte: plano de aplicação dos recursos, previsão de receitas e despesas e plano de investimentos.

Para verificar se a fundação desempenha de fato as atividades propostas para o fim social além das documentações os auditores realizam a chamada auditoria in loco, que constitui uma verificação nas instalações da fundação.

Página 137 Caderno de Ciências Sociais Aplicadas, Vitória da Conquista/BA, vol. 15, n 26, ano 15, p. 132-150, jul/dez 2018. 


\section{- Cadernos de Ciénclas SOCIAIS APLICADAS}

O Promotor de Justiça, com o suporte no trabalho dos auditores, decide pela aprovação ou não das contas da fundação, arquivará o expediente ou tomará as providencias judiciais e extrajudiciais que julgar necessárias, consoante o art. 39 da Resolução 2.434/02.

Para sintetizar o processo de prestação de contas, com as exigências solicitadas às fundações pelo MP bem como a verificação da auditoria, tem-se a figura 2:

Figura 2 - Processo de prestação de contas ao Ministério Público

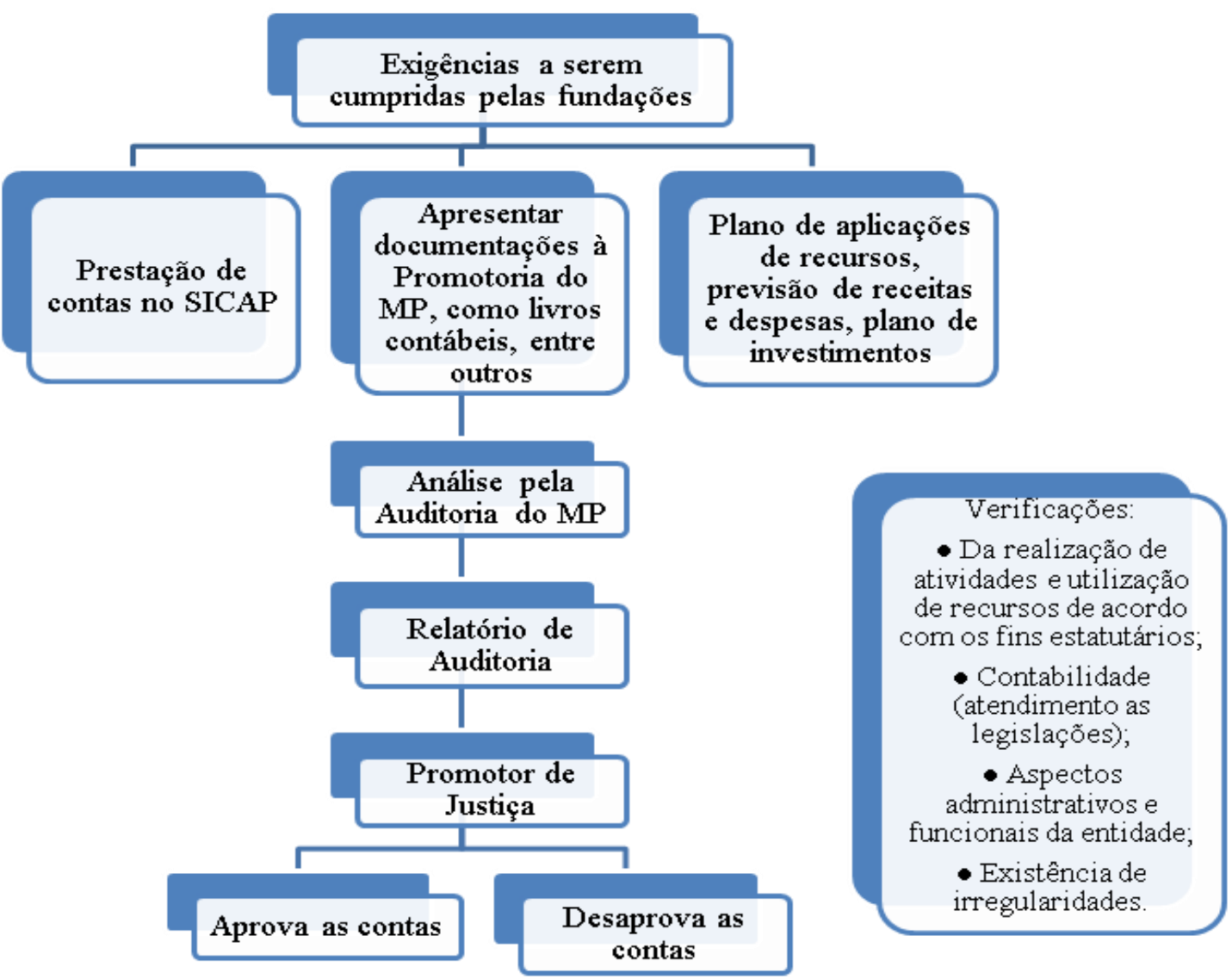

Fonte: Dados coletados em pesquisa

As etapas do processo de auditoria podem variar de acordo com as particularidades inerentes a cada entidade e também ao próprio método do auditor que desenvolve os trabalhos. De forma geral, os procedimentos de verificação seguem as etapas da figura 3: 


\section{Cadernos de Ciências SOCIAIS APLICADAS}

Figura 3 - Síntese das etapas de verificação das documentações

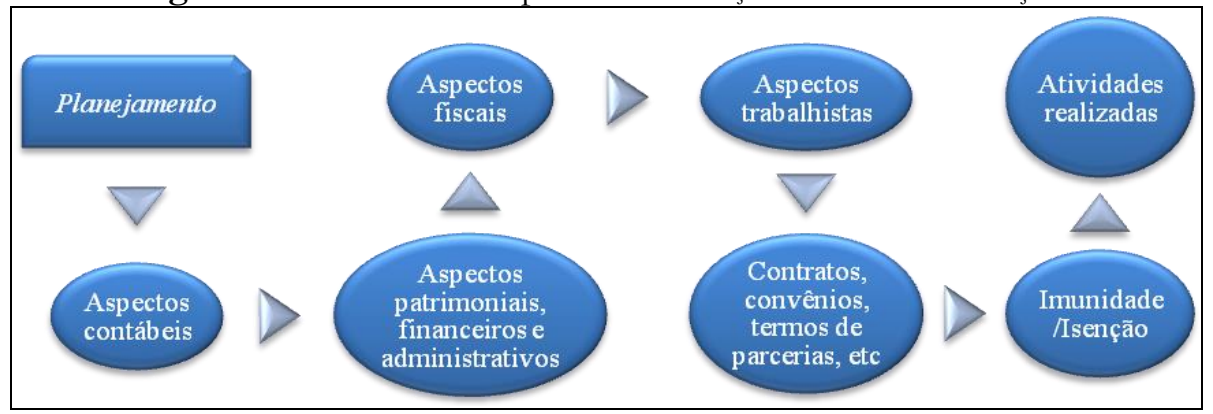

Fonte: Elaboração própria.

O planejamento pressupõe a realização de uma análise da fundação a ser auditada para determinar o critério e a extensão dos exames. O item aspectos contábeis relaciona-se às verificações das formalidades nos livros contábeis, prestação de contas firmada por contador registrado no CRC, atendimento aos princípios e demais normatizações contábeis aplicadas às fundações, adequação de plano de contas, entre outros. Em aspectos patrimoniais, financeiros e administrativos ocorrem as verificações de controles internos e administrativos, financeiro, de estoques, de imobilizado e do patrimônio social. Os aspectos fiscais relacionam-se com as verificações de retenção e recolhimento de impostos/contribuições bem como declarações obrigatórias. Em aspectos trabalhistas, são verificados os cálculos das verbas trabalhistas e as documentações como a Relação Anual de Informações Sociais (RAIS). Quanto aos contratos, convênios, termos de parcerias, entre outros é realizada avaliação dos instrumentos jurídicos. Em imunidade/isenção verifica-se se existem benefícios garantidos pela Constituição Federal ou por lei aplicáveis a entidade em análise. Nas atividades realizadas inclui-se a análise das atividades realizadas no exercício em verificação, quanto aos aspectos qualitativos e quantitativos, adequação dos recursos aplicados aos resultados obtidos, entre outros.

Pelo exposto verifica-se que a forma como é conduzido o processo de prestação de contas do MP, a exemplo do Estado do Paraná, vai além da fiscalização pelos técnicos, mas tem uma característica de agente apoiador das fundações privadas.

\section{Trajetória político-institucional do Ministério Público}

Em 1988, a Constituição Federal (CF), então promulgada, reconstituiu o ordenamento constitucional do Brasil e definiu no artigo 27 o MP como "instituição permanente, essencial à função

Página 139 Caderno de Ciências Sociais Aplicadas, Vitória da Conquista/BA, vol. 15, n 26, ano 15, p. 132-150, jul/dez 2018. 
jurisdicional do Estado, incumbindo-lhe a defesa da ordem jurídica, do regime democrático e dos interesses sociais e individuais indisponíveis” (BRASIL, 1988).

Sírio (2016, p. 2) afirma que após esse emergir do MP do ponto de vista da legitimidade democrática, ampliou-se a expressão institucional do órgão ministerial e lhe foram conferidos “os meios necessários à concessão de sua destinação constitucional atendendo-se, finalmente, a antiga reivindicação da própria sociedade”.

Politicamente, para que o MP possa desempenhar seu papel na sociedade a CF, no seu artigo 127, assegurou sua independência funcional considerado requisito de "fundamental importância para a manutenção e cumprimento dos objetivos constitucionais e institucionais" (TAVARES, 2016, p. 2).

Assim, o MP é órgão independente ou autônomo, como afirma Aguiar Júnior (1972). Segundo o autor, o MP é autônomo formal e materialmente, porquanto não pertence ao Judiciário, Legislativo, nem tampouco ao Executivo, mas com relação a este último extrai de sua soberania a capacidade para agir e oficiar.

Cabe ao MP o poder de requerer informações e documentos para instruir os procedimentos administrativos de sua competência. Infere-se a partir do exposto, que o MP possui material e objeto de análise dos autos (informações e documentos) para concluir sobre a regularidade do que se avalia e para emitir parecer sobre uma melhor forma de adequação e ainda "concomitantemente, os remédios processuais adequados à realização judicial de suas pretensões” (MACHADO33, 1989 apud RESENDE, 2007, p. 127-128).

Perante as discussões sobre o poder de investigação criminal do órgão do MP, faz-se pertinente mencionar Sírio (2016, p. 2), que pondera:

É indisputável que o Ministério Público ostenta, em face do ordenamento constitucional vigente, destacada posição na estrutura do Poder. A independência institucional, que constitui uma de suas expressivas prerrogativas, garante-lhe o livre desempenho, em toda a sua plenitude, das atribuições que lhe foram conferidas. Cumpre, por isso mesmo, neste expressivo momento histórico em que o Ministério Público se situa entre o seu passado e o seu futuro, refletir sobre a natureza da missão institucional que a ele incumbe desempenhar no seio de uma sociedade que, agora, emerge para a experiência concreta de uma vida democrática.

\footnotetext{
${ }^{3}$ MACHADO, Antônio Cláudio da Costa. A Intervenção do Ministério Público no Processo Civil Brasileiro. $1^{\mathrm{a}}$ ed. São Paulo: Saraiva, 1989.
}

Página 140 Caderno de Ciências Sociais Aplicadas, Vitória da Conquista/BA, vol. 15, n 26, ano 15, p. 132-150, jul/dez 2018. 
Assim, conclui-se que o MP “é uma Instituição independente que cuida da proteção das liberdades civis e democráticas, buscando com sua ação assegurar e efetivar os direitos individuais e sociais indisponíveis, como sua missão constitucional” (MPPR, 2009).

\section{Metodologia}

De acordo com a classificação de Gil (2002) e Demo (2000) sobre a natureza do problema de pesquisa e partindo da premissa de que o trabalho visa contribuir para o desenvolvimento do debate em torno da atuação do Ministério Público e sua ação fiscalizatória sobre as fundações privadas, entende-se que esse artigo deva estar classificado como empírico-teórico.

Trata-se de uma pesquisa qualitativa, uma vez que se utiliza de dados qualitativos para apresentar a complexidade do problema proposto e colabora para o entendimento das particularidades constantes nos apontamentos do MP e as adequações realizadas pelas fundações privadas.

A pesquisa qualitativa é rigorosa, exige trabalho intenso, integridade e um exercício de julgamento por parte do investigador, que inclui a reflexividade e a atenção aos casos desviantes e à relevância (AUGUSTO, 2014). Cabe ressaltar que a pesquisa qualitativa depende do pesquisador na produção do conhecimento: habilidade, conhecimento e rigor na coleta dos dados (POZZEBON, 2014).

O estudo classifica-se como descritivo e envolve a análise e interpretação dos resultados registrados nos relatórios de auditoria que foram utilizados para o atendimento da proposta deste estudo.

Para esta pesquisa foi feito um recorte espacial cuja fonte de pesquisa foi o MPPR, limitando-se a análise à $13^{a}$ Promotoria de Justiça da Comarca de Maringá Estado do Paraná. O foco da análise foi delimitar o estudo a três fundações privadas, cuja auditoria é de competência da $13^{\text {a }}$ Promotoria de Justiça. Assim, a estratégia da pesquisa é o estudo de caso que segundo Stake (2005) é um caminho natural para conduzir pesquisas qualitativas.

A escolha em investigar essas fundações se deu primeiramente pela diversidade de atividades fins desenvolvidas por cada uma. Selecionou-se uma fundação com atuação na área da saúde, outra na área da educação e a última desenvolve atividade de rádio com fins religiosos. Além disso, foram escolhidas essas três fundações em decorrência de que tinham uma trajetória de diversos anos

Página 141 Caderno de Ciências Sociais Aplicadas, Vitória da Conquista/BA, vol. 15, n 26, ano 15, p. 132-150, jul/dez 2018. 
consecutivos de prestações de serviço na comunidade e mantinham uma regularidade na prestação de contas. Os nomes das fundações não serão divulgados para garantir de sigilo das informações.

Os dados do estudo foram coletados junto aos técnicos e ao Promotor de Justiça, por meio de consultas aos procedimentos administrativos de prestações de contas das fundações analisadas. Foram analisados os relatórios de auditoria emitidos, os últimos cinco exercícios de prestações de contas encerradas, isto é, que continham parecer final do Promotor de Justiça pela aprovação ou desaprovação das contas.

\section{Caracterização das fundações e os apontamentos em relatórios de auditoria}

Foram estudadas as três fundações e os últimos cinco exercícios de prestações de contas encerradas, visto que continham parecer final do Promotor de Justiça pela aprovação ou não das contas. Para fins de garantir o sigilo, foram nomeadas pelos nomes fictícios X, Y e Z.

A fundação X possui fins religiosos com atuação principal na área da saúde. Os pacientes são encaminhados pelos hospitais da cidade de Maringá para que tenham tratamento de sua enfermidade contando com a estrutura da fundação que inclui alimentação, transporte e apoio espiritual.

A Fundação Y tem atuação voltada para a educação e cultura. Suas atividades principais relacionam-se ao ensino e utiliza-se de instrumento de comunicação de massa em suas atividades.

Já a Fundação Z tem fins religiosos como principais, e, para tanto, utiliza-se da estrutura de sua rádio para que as atividades sejam realizadas. As atividades relacionam-se à disponibilização de informação as pessoas, atreladas aos objetivos de evangelização e caráter social. A rádio é acompanhada por pessoas do Brasil e de outros países, pois seu acesso é disponibilizado pela internet.

Conforme as áreas de verificação dos auditores demonstrada na figura 3, apresenta-se no quadro 1, a seguir, o número de apontamentos identificados nos relatórios de auditoria preliminares.

Página 142 Caderno de Ciências Sociais Aplicadas, Vitória da Conquista/BA, vol. 15, n 26, ano 15, p. 132-150, jul/dez 2018. 


\section{- Cadernos de Ciénclas SOCIAIS APLICADAS}

Quadro 1 - Apontamentos realizados em Relatórios por área de verificação

\begin{tabular}{|c|c|c|c|c|c|}
\hline \multirow{2}{*}{ ÁREAS ANALISADAS } & \multirow{2}{*}{ Fundação X } & \multirow{2}{*}{ Fundação $Y$} & \multirow{2}{*}{ Fundação Z } & \multicolumn{2}{|c|}{ Total } \\
\hline & & & & Qtd. & $\%$ \\
\hline Aspectos contábeis & 12 & 41 & 54 & 107 & 55,70 \\
\hline $\begin{array}{l}\text { Aspectos patrimoniais, } \\
\text { financeiros e administrativos }\end{array}$ & 8 & 9 & 16 & 33 & 17,20 \\
\hline Aspectos fiscais & 2 & 0 & 0 & 2 & 1,00 \\
\hline Aspectos trabalhistas & 12 & 11 & 17 & 40 & 20,80 \\
\hline $\begin{array}{c}\text { Contratos, convênios, termos } \\
\text { de parcerias, etc }\end{array}$ & 3 & 0 & 0 & 3 & 1,60 \\
\hline Atividades realizadas & 5 & 1 & 1 & 7 & 3,60 \\
\hline Imunidade/Isenção & 0 & 0 & 0 & 0 & 0,00 \\
\hline Total & 42 & 62 & 88 & 192 & 100,00 \\
\hline
\end{tabular}

Fonte: Dados coletados em documentos do MP

O maior número de apontamentos refere-se aos aspectos contábeis (55,7\%), seguido dos trabalhistas $(20,8 \%)$ e dos patrimoniais, financeiros e administrativos $(17,2 \%)$. Devido à relevância dos números apresentados das não conformidades relacionadas aos aspectos contábeis (12 apontamentos para a Fundação X, 41 para a Fundação Y e 54 para a Fundação Z), demonstra-se, no quadro 2, maior detalhamento nesta área de verificação.

Quadro 2 - Tipos de apontamentos da classificação por áreas de verificação: aspectos contábeis

\section{Tipo de apontamentos}

Falta de documentação comprobatória.

Pagamentos efetuados com dinheiro da Fundação, não condizentes à entidade.

Classificações em contas contábeis inadequadas.

Erros em conciliação bancária.

Falta de contabilização de operações.

Registro de operações em duplicidade.

Problemas formais de documentação (documentação sem validade fiscal, sem preenchimento, etc)

Documentação comprobatória em nome de outra pessoa (física ou jurídica).

Contabilizações em datas inadequadas.

Contabilizações em valores incorretos.

Fonte: Síntese de dados coletados em pesquisa junto ao MP

Página 143 Caderno de Ciências Sociais Aplicadas, Vitória da Conquista/BA, vol. 15, n 26, ano 15, p. 132-150, jul/dez 2018. 


\section{Cadernos de Ciências SOCIAIS APLICADAS}

É comum haver apontamentos que solicitam esclarecimentos adicionais nos relatórios preliminares elaborados pelos auditores, conforme pode-se visualizar no quadro 2. Os esclarecimentos requeridos podem referir-se às situações que podem ser melhoradas, complementadas ou sugestões que podem ou não ser acatadas pelas fundações.

Desta forma, os apontamentos feitos em relatório preliminar ou outro relatório de auditoria não se referem necessariamente às situações de descumprimento de legislação e, mesmo quando representam, podem ser esclarecidas ou não ser relevantes o suficiente para comprometer toda a prestação de contas, ou seja, ter apontamentos em relatório de auditoria não implica necessariamente reprovação das contas.

As evidências que necessitam de esclarecimentos, novas documentações, ressarcimento pelo Presidente à época dos fatos ou algum outro tipo de complemento para a solução dos fatos, tornam necessária a emissão de novo relatório de auditoria após análise das considerações apresentadas pela entidade em análise, e segue-se nesse processo até que se tenha um parecer final.

As prestações de contas das fundações devem estar em conformidade com os princípios e normas contábeis, Lei 4.320/64, Resolução 2.434/02 e demais legislações aplicáveis a casos isolados. Desta forma, os auditores devem verificar a adequação das prestações de contas a estas regulamentações. Apresentam-se no quadro 3, os apontamentos cujas soluções efetivamente foram condicionantes à aprovação das contas.

Quadro 3 - Apontamentos em desacordo a legislações

\begin{tabular}{|c|c|c|c|c|c|}
\hline $\begin{array}{l}\text { Apontamentos } \\
\text { legislações/norn }\end{array}$ & $\begin{array}{l}\text { ondicionante } \\
\text { tivos }\end{array}$ & à & vação & is con & s sob a ótica das \\
\hline $\begin{array}{l}\text { LEGISLAÇÃO } \\
\text { / FUNDAÇÃO }\end{array}$ & $\begin{array}{c}\text { Princípios } \\
\text { Contábeis - } \\
\text { Resoluções } \\
750 / 93 \text { e } \\
1.282 / 10\end{array}$ & NBC & $\begin{array}{c}\text { Resolução } \\
2.434 / 02\end{array}$ & Outras & Qual(is) \\
\hline Fundação $X$ & 11 & 0 & 5 & 5 & $\begin{array}{l}\text { L. C. Municipal } 677 / 2007 \\
\text { (S. T. de Maringá); Lei } \\
\text { 6.404/76 e alterações. }\end{array}$ \\
\hline Fundação $Y$ & 27 & 1 & 7 & 4 & $\begin{array}{l}\text { L. C. Municipal } 677 / 2007 \\
\text { (S. T. de Maringá); Lei } \\
6.404 / 76 \text { e alterações. }\end{array}$ \\
\hline Fundação $Z$ & 47 & 0 & 9 & 17 & $\begin{array}{l}\text { Lei } 6.404 / 76 \text {; } \\
\text { Consolidação das Leis do } \\
\text { Trabalho. }\end{array}$ \\
\hline
\end{tabular}

Fonte: Dados coletados em pesquisa junto ao MP

Página 144 Caderno de Ciências Sociais Aplicadas, Vitória da Conquista/BA, vol. 15, n 26, ano 15, p. 132-150, jul/dez 2018. 
Pode-se constatar que o maior número de não conformidades está ligado aos aspectos contábeis. São situações que se apresentaram em desacordo com os princípios de contabilidade, representando 63,9\%, isto é, 85 apontamentos de um total de 133. Enquanto os apontamentos referentes às NBC não chegam a 1\%, a Resolução 2.434/02 representa 15,8\% e as outras legislações $19,5 \%$.

Cabe salientar que essas evidências de descumprimento aos princípios de contabilidade referemse, em sua grande maioria, a problemas formais cuja solução depende apenas de ajustes de controle interno por parte das fundações e a situações de desacordo ao que concerne a tempestividade e integridade preconizadas no princípio da oportunidade, conforme Resolução 750/93.

Conforme analisado, para as três entidades selecionadas, o último exercício que se encontrava encerrado quando das visitas à $13^{\text {a }}$ Promotoria de Justiça realizadas em 2012, foram os exercícios de 2008 para as Fundações X e Y e 2006 para a Fundação Z. Com este fato, verifica-se uma demora no processo de prestação de contas. De acordo com o art. 34 da Resolução 2.434/02 “a Fundação terá até o último dia útil do mês de junho do ano subsequente ao exercício financeiro para apresentar a Prestação de Contas à Promotoria das Fundações". Então, apesar do tempo assinado às fundações para que apresentem suas contas, o Órgão Ministerial apresenta certa dificuldade em analisá-las mais rapidamente.

De uma forma geral, o MP encontrou nas três fundações analisadas o mesmo tipo de apontamento em relatório de auditoria, destacando-se como os mais recorrentes: falta de controle de imobilizado/depreciação; apresentação de documentação em via não original, em nome de outra pessoa (física ou jurídica), sem dados de identificação da fundação e/ou produto/serviço adquirido; contabilizações em contas contábeis inadequadas, em datas incorretas, sem documentação suporte aos registros; falta de apresentação de documentação destacando-se documentação comprobatória de movimentação bancária e de relações trabalhistas.

$\mathrm{Na}$ sequência, apresentam-se no quadro 4 as principais não conformidades identificadas:

Página 145 Caderno de Ciências Sociais Aplicadas, Vitória da Conquista/BA, vol. 15, n 26, ano 15, p. 132-150, jul/dez 2018. 


\section{- Cadernos de Ciénclas SOCIAIS APLICADAS}

Quadro 4 - Síntese de apontamentos identificados nas três entidades analisadas

\begin{tabular}{|l|}
\hline \multicolumn{1}{|c|}{ PRINCIPAIS NÃO CONFORMIDADES } \\
\hline Despesa(s) fora do objeto de atuação \\
\hline Falta de apresentação de documentação suporte à contabilidade \\
\hline Falta de comprovação de pagamentos \\
\hline $\begin{array}{l}\text { Documentação sem validade fiscal; em nome de outra pessoa; sem informações do que foi } \\
\text { comprado. }\end{array}$ \\
\hline Contabilizações incorretas, inadequadas ou faltantes \\
\hline Falta de autonomia em relação ao ente instituidor \\
\hline Falta de controle de imobilizado e depreciações \\
\hline Falta de recolhimento de tributos \\
\hline Necessidade de esclarecimentos sobre situações e despesas \\
\hline Diferença de valor entre relatórios/documentos \\
\hline Falta de apresentação de Relatório de Atividades e relação com pessoas atendidas \\
\hline Falta de apresentação de atas de reunião de órgãos internos e administrativos da Fundação \\
\hline Falta de apresentação de Relatório de órgão interno com a aprovação das contas do exercício. \\
\hline
\end{tabular}

Fonte: Síntese de dados coletados em pesquisa (2012)

O quadro 4 sintetiza o que ocorreu nas três fundações analisadas. Apresentaram, de uma forma geral, o mesmo tipo de apontamento em relatório de auditoria, destacando-se como os mais recorrentes os seguintes: falta de controle de imobilizado/depreciação; apresentação de documentação em via não original, em nome de outra pessoa (física ou jurídica), sem dados de identificação da fundação e/ou produto/serviço adquirido; contabilizações em contas contábeis inadequadas, em datas incorretas, sem documentação suporte aos registros; falta de apresentação de documentação destacando-se documentação comprobatória de movimentação bancária e de relações trabalhistas. Destaca-se que as irregularidades na prestação de contas pode levar os gestores a responderem por improbidade administrativa estando sujeitos às sansões previstas na Lei 8.429/92.

Com fundamento nos resultados da pesquisa é possível sugerir algumas medidas visando à melhoria na transparência nas prestações de contas: (a) controle no envio de documentação aos auditores do MP de forma a atendar as exigências para a conclusão dos trabalhos; (b) melhor gerenciamento da documentação comprobatória; (c) aprofundamento do conhecimento para pleno atendimento aos princípios e normas brasileiras de contabilidade, Lei 4.320/64, resolução 2.434/02 e demais legislações, e melhor controle contábil; (d) Controle no processo de compras, para que não seja utilizado dinheiro da entidade para gastos que não fazem parte dos fins previstos em seu estatuto; (e) esclarecimentos aos auditores sobre gastos que possivelmente fogem à normalidade, mas que por

Página 146 Caderno de Ciências Sociais Aplicadas, Vitória da Conquista/BA, vol. 15, nº 26, ano 15, p. 132-150, jul/dez 2018. 
situação específica ocorreram e não são estranhos às atividades da entidade. Desta forma, evita-se o apontamento em relatório de auditoria, uma vez que se tratam de despesas que devem ser esclarecidas ou ressarcidas à entidade pelo presidente à época dos fatos.

Sobre o controle, ao enviar a documentação ao MP, as fundações poderiam realizar uma checagem prévia para que nenhuma documentação faltasse e atrasasse todo o processo. Por exemplo, se a fundação possui cinco contas bancárias, deve encaminhar os documentos comprobatórios (extratos) de todas as contas, e se essas possuírem além de conta corrente, poupança ou outros investimentos vinculados, também devem ser encaminhados estes demonstrativos.

Para que exista um controle efetivo quanto à documentação comprobatória, para que esta seja válida e com preenchimento correto, poderiam ser disponibilizadas informações a todas as pessoas envolvidas com o processo de compras.

É imprescindível para que se cumpram determinadas regras, primeiramente, conhecê-las bem, portanto é pressuposto para que as prestações de contas avancem em qualidade que os conhecimentos contábeis e outros relacionados sejam aprofundados.

As pessoas envolvidas com compras e os gestores devem estar atentos à forma como estão sendo utilizados os recursos da fundação. Se a entidade é voltada à saúde, é natural que tenha gastos relacionados a esta área como medicamentos, equipamentos médicos, entre outros, além é claro das despesas de manutenção da entidade e gastos administrativos e fiscais. Mas o que deve ficar claro é que gastos como churrasco para dirigentes, presentes, bens supérfluos entre outros exemplos, não devem fazer parte do escopo de utilização do dinheiro da fundação.

\section{Considerações finais}

Em consulta aos relatórios de auditoria emitidos para prestações de contas de outras entidades e em diálogo com os auditores do MP, esta pesquisa conclui que o tipo de inconsistência encontrada nas três entidades analisadas é comum e frequente. Em resposta ao problema da pesquisa, verificou-se que o que compromete as prestações de contas das fundações são problemas com a falta de documentações, a sua respectiva escrituração e a realização de gastos que não condizem com as finalidades propostas no estatuto. Portanto, infere-se que há falta de pessoal técnico qualificado ao trabalho contábil e administrativo nas fundações.

Página 147 Caderno de Ciências Sociais Aplicadas, Vitória da Conquista/BA, vol. 15, n² 26, ano 15, p. 132-150, jul/dez 2018. 
Conclui-se também que, quando se analisa o teor das não conformidades apontadas nos relatórios de auditoria das fundações analisadas, admitindo-se um pouco da subjetividade que faz parte das pesquisas qualitativas e do próprio trabalho dos auditores, verifica-se que se trata em sua grande maioria, de problemas cuja solução depende apenas de uma melhor gestão dos recursos. No entanto, caso não se identificassem tantos casos passíveis de justificativas, documentações completares e irregularidades, certamente o processo de prestações de contas poderia ser mais rapidamente concluído.

Para atendimento do objetivo da pesquisa foram analisados os relatórios de auditoria emitidos no MPPR para fundações privadas da Comarca de Maringá e foi possível concluir que: (a) as fundações analisadas prestam serviços relevantes à sociedade, cada qual em sua área de atuação. Identificou-se que as três entidades analisadas apresentaram não conformidades em suas prestações de contas, mas, segundo a Promotoria, não lhes falta o mérito do serviço prestado; (b) as inconformidades nas prestações de contas encontram-se naqueles apontamentos em relatório de auditoria cuja solução foi fator condicionante para que as contas fossem aprovadas e encontram-se fundamentados em legislação pertinente; (c) as prestações de contas das três fundações analisadas não seguem fielmente os preceitos legais descritos nas regulamentações; e (d) os auditores solicitaram diversas vezes a mesma correção até que estive dentro da legalidade.

Os tipos de não conformidades levantados neste estudo apontam que há necessidade de pessoal contábil qualificado para atuação nas entidades, para que erros primários como os observados nas prestações de contas das fundações deem lugar ao fiel cumprimento das legislações e agilizem todo o processo de análise dos auditores (que são servidores pagos com dinheiro público que poderiam otimizar seu tempo de trabalho).

Verifica-se que há a necessidade de mudanças no processo de prestação de contas ao MP para que possa haver diminuição/eliminação dos apontamentos em relatório de auditoria, já que as não conformidades atrasam o processo de prestação de contas e comprometem a veracidade e transparência das informações.

Por fim, conclui-se que o MPPR, pelo trabalho realizado na Comarca de Maringá, está desempenhando múltipla atuação que, além de verificar a legalidade nos procedimentos de auditoria, assume a função de incentivar e apoiar as fundações por meio da proteção do patrimônio destas entidades permitindo inúmeras adequações até que haja a conformidade nas prestações de contas.

Página 148 Caderno de Ciências Sociais Aplicadas, Vitória da Conquista/BA, vol. 15, n 26, ano 15, p. 132-150, jul/dez 2018. 


\section{Referências}

AUGUSTO, A. Metodologias quantitativas/metodologias qualitativas: mais do que uma questão de preferência. Fórum Sociológico, n. 24, 2014.

BETTIOL JÚNIOR, A. Formação e destinação do resultado em entidades do terceiro setor: um estudo de caso. 2005. 116f. Dissertação (Mestrado) - Universidade de São Paulo, São Paulo, 2005.

BRASIL. Lei 4.320/64. Casa Civil. Institui normas gerais de direito financeiro para elaboração e controle dos orçamentos e balanços da União, dos Estados, dos Municípios e do Distrito Federal. Brasília, 1964.

BRASIL. Constituição da República Federativa do Brasil. Diário Oficial da República

Federativa do Brasil, Brasília, 1988.

BRASIL. Lei n. 8.429/92. Dispõe sobre as sanções aplicáveis aos agentes públicos nos casos de enriquecimento ilícito no exercício de mandato, cargo, emprego ou função na administração pública direta, indireta ou fundacional. Brasília. 1992.

BRASIL. Resolução 837/99. Conselho Federal de Contabilidade. Aprova os aspectos contábeis da NBC T 10.4 que trata das Fundações. Brasília, 1999.

BRASIL. Lei n. ${ }^{\circ}$ 10.406/2002. Institui o código civil. Diário Oficial da República Federativa do Brasil, Brasília, 2002.

BRITTES, R. M. Prescrição e prestação de contas das fundações junto ao Ministério Público. Disponível em: <http://www.fundacoes.mppr.mp.br/arquivos/File/

prescricao_prestacao_contas_fundacoes_rosana.pdf>. Acesso em: 10 fev. 2016.

CFC - Conselho Federal de Contabilidade. Manual de procedimentos contábeis para fundações e entidades de interesse social. $2^{\mathrm{a}}$ ed. reimp. Brasília - DF: CFC, 2008.

DEMO, P. Metodologia do conhecimento científico. São Paulo, Atlas, 2000.

GIL, A. C. Como elaborar projetos de pesquisa. São Paulo, Atlas, 2002.

MELO, T. F. de. Fiscalização das contas das fundações pelo Ministério Público estadual. Revista Acadêmica da Escola Superior do Ministério Público do Estado do Ceará. Ceará, ano II, n. 1, 2010.

MPPR. MINISTÉRIO PÚBLICO DO ESTADO DO PARANÁ. O Ministério Público. 2009. Disponível em: <http://www.mp.pr.gov.br/. Acesso em: 05 fev. 2016.

Página 149 Caderno de Ciências Sociais Aplicadas, Vitória da Conquista/BA, vol. 15, n 26, ano 15, p. 132-150, jul/dez 2018. 


\section{- Cadernos de CiêncIas SOCIAIS APLICADAS}

MINISTÉRIO PÚBLICO DO ESTADO DO PARANÁ. Resolução 2.434/02. 2014. Disponível em: <http://www.fundacoes.caop.mp.pr.gov.br/. Acesso em: 02 fev. 2016.

POZZEBON, M. Advanced Topics in Qualitative Research. Doing and publishing qualitative research in international journals. Fundação Getulio Vargas, 2014.

RESENDE, T. A. A necessidade do velamento do Ministério Público pelas atividades das organizações de direito privado sem fins lucrativos, inclusive das associações. In: Congresso Estadual do Ministério Público de Minas Gerais, 2007. Minas Gerais: Associação Mineira do Ministério Público, 2007.

SÍRIO, A. I. C. O Ministério Público e sua destinação constitucional.

Disponível em: <http://www.mpce.mp.br/servicos. Acesso em: 30 mar. 2016.

STAKE, R. E. The art of case study researche. Thousand Oaks: Sage Publications, 2005.

TORRES, L. V. O Sistema de Cadastro e Prestação de Contas (SICAP) como instrumento de accountability em fundações: um estudo com fundações privadas da comarca de Ribeirão Preto. 2007. Dissertação (Mestrado) - Faculdade de Economia, Administração e Contabilidade de Ribeirão Preto, Universidade de São Paulo, Ribeirão Preto, 2007.

TAVARES, G. M. O Ministério Público e a natureza jurídica de sua intervenção no processo civil. Disponível em: <http://jus.com.br/artigos/7520/o-ministerio-publico-e-anatureza- juridica>. Acesso em: 10 mar. 2016. 